\title{
The efficacy and safety of desflurane versus sevoflurane in elderly patients during general anaesthesia: A meta-analysis randomized controlled trials
}

\author{
Yiping Li ${ }^{1}$, Ruiming Deng', Juan Zhou ${ }^{1}$, Shifu $\mathrm{Hu}^{2}$ and Aiping Ouyang ${ }^{*}$ \\ ${ }^{1}$ The Affiliated Ganzhou Hospital of Nanchang University, China \\ ${ }^{2}$ Family Planning Research Institute, Tongji Medical College, Huazhong University of Science and Technology, China
}

\begin{abstract}
The objective of the study was to systematically screen the literature and to identify of the results of randomized controlled trials (RCTs) comparing the efficacy and safety of desflurane versus sevoflurane in elderly patients during general anaesthesia. Databases including PUBMED, EMBASE, Web of Science and Cochrane Library were searched until July 2018 to identify relevant studies. Two authors independently reviewed each study. After literature screening and data extraction, a meta-analysis was conducted using the RevMan 5.2 software. Five RCTs, including 324 patients, met the inclusion criteria and were included in the final analysis. Our pooled analysis showed that elderly patients during desflurane general anaesthesia could reduce time taken to open eyes (SMD, -0.63 ; $95 \% \mathrm{CI},-1.23$ to -0.03 ; $\mathrm{P}=0.04$ ), follow commands (SMD, $-0.97 ; 95 \% \mathrm{CI},-1.76$ to $-0.19 ; \mathrm{P}=0.01)$, extubation (SMD, $-0.77 ; 95 \% \mathrm{CI},-1.35$ to $-0.19 ; \mathrm{P}=0.009)$ and orientation (SMD, -1.49 ; $95 \% \mathrm{CI},-2.43$ to -0.54$)$. However, there was no difference between desflurane and sevoflurane groups with regard to anesthesia time (SMD, $-0.10 ; 95 \% \mathrm{CI},-0.35$ to $0.15 ; \mathrm{P}=0.43$ ) and the length of postanesthetic care unit (PACU) PACU stay (SMD, $-4.65 ; 95 \% \mathrm{CI},-10.31$ to 1 ; $\mathrm{P}=0.11$ ). Our results show that elderly patients during desflurane general anaesthesia offers several potential advantages over anaesthesia in terms of the time to open the eyes, follow commands, extubation and orientation. However both anesthetics appear to be equivalent with regard to the anesthesia time and length of PACU stay.
\end{abstract}

\section{Introduction}

With increasing life expectancy, more and more patients over 65 years of age account for an ever increasing need of surgical procedures, especially in developed countries [1,2]. Ageing has be recognized for years as a process of intrinsic deterioration that results in functional and structural with an irreversible and progressive changes $[3,4]$. These changes usually result in increasing the morbidity of the elderly patients and delayed recovery from general anesthesia [5]. Furthermore, Dogru et al have reported that the postoperative recovery from general anesthesia is related to the time spent in the postanesthetic care unit (PACU) [6]. However, owing to the service fees of PACU are double the ward fees [5]. Normally, shortening the time of a PACU stay decreases the service fees, which has an obvious economic benefit [7]. Additionally, using fast elimination anesthetics may lead to less postoperative cognitive dysfunction and faster recovery from anesthesia $[8,9]$. Therefore, anesthesia for elderly patients poses a grim challenge for the anesthesiologist and surgeons, due to reduced respiratory reserves and cardiovascular and associated organ system diseases.

Currently, new volatile anaesthetics such as sevoflurane and desflurane are in widespread clinical use for maintenance of general anesthesia $[10,11]$. The advantage of these anaesthetics is their low blood solubility, which accounts for its extremely rapid onset of action and recovery from general anesthesia $[10,12,13]$. Since 2001, several randomized controlled trials (RCT) have been carried out to assess the efficiency and safety of desflurane and sevoflurane anesthesia in elderly patients $[1,8,14-16]$. As each type of anesthesia has some advantages and/or disadvantages, and the conclusions have not been completely consistent.
Therefore, the present meta-analysis was performed to systematically compare the efficacy and safety of desflurane and sevoflurane in elderly patients under general anesthesia based on currently available clinical trials. We hope these findings would produce more interest in this topic and provide some help for anesthesiologists, surgeons, elderly patients, and policymakers in making relevant decisions in the future.

\section{Materials and methods}

\section{Search strategy}

The PUBMED, EMBASE, Web of Science and Cochrane Library databases were systematically searched by two independent authors (LYP and DRM) from inception to July 2018. Only articles published in English language were screened. The search keywords were used as follows: "general anaesthesia", "sevoflurane", "desflurane", "elderly patients", "elderly", "randomized controlled trials" and "RCT". In addition, references list of retrieved articles were also searched manually.

\section{Inclusion and exclusion criteria}

Eligibility studies that met the following criteria were included: (1) randomized controlled trial; (2) desflurane versus sevoflurane; (3)

*Correspondence to: Aiping Ouyang, The Affiliated Ganzhou Hospital of Nanchang University, Ganzhou, Jiangxi, 341000, China, Tel: 86-0797-5889027, Fax: 86-0797-5889027, E-mail: Dahai_ouyang@sina.com

Key words: desflurane, sevoflurane, efficacy, safety, elderly patients, meta-analysis Received: August 04, 2018; Accepted: August 22, 2018; Published: August 27, 2018 
elderly patient population ( $>65$ years); (4) access to the full text of the study and available data for analysis; (5) including at least one of the following outcomes: Anesthesia time; open eyes, extubation, following commands, orientation and postanesthetic care unit (PACU) time. The exclusion criteria were list as follow: (1) abstracts, case reports, reviews and letters; (2) not randomized controlled trial; (3) animal experiment. (4) Unable to extract original data from the study.

\section{Data extraction and quality assessment}

Data were independently extracted by two reviewers (LYP and DRM). The following data items were extracted from each identified study: first author, year of publication, country, number of participants, ages, sex, main results. A quality evaluation of each RCT was conducted by two reviewers (ZJ and HSF) according to the Cochrane Collaboration tool [17]. The following items were used to assess the "risk of bias" of each RCT: random sequence generation, allocation concealment, blinding, incomplete outcome data, free of selective reporting and other bias. Discrepancies were settled by consensus after discussion with one other author (OYAP) when necessary.

\section{Data synthesis and analysis}

All statistical analyses were conducted using Review Manager 5.2 (Cochrane Collaboration). We estimated the standardized mean difference (SMD) for continuous outcomes with a $95 \%$ confidence interval (CI). Heterogeneity across studies was examined using the Chi squared test and $I^{2}$ statistics. If no significant heterogeneity was detected $\left(\mathrm{I}^{2}<50 \%\right)$, fixed-effect models was applied to pool data. Otherwise, the random-effect model was used.

\section{Results}

\section{Study characteristics}

Initially, 658 articles were screened through the search of electronic databases. By scanning titles and abstracts, 645 apparently irrelevant reports were excluded. 8 articles were further excluded after carefully reading full text review. Finally, only five RCTs involving 324 patients were included according to the eligibility criteria. Of the patients, 165 and 159 were classified into the desflurane and sevoflurane groups, respectively. The flow diagram of study selection process is presented in figure 1 . The basic characteristics of each included study can be seen in table 1. Furthermore, the risk of bias across all RCTs is presented in table 2 .

\section{Anesthesia time}

Four of the included studies $[1,8,14,16]$ reported data on the anesthesia time. The results are presented in figure $2 \mathrm{a}$. There was no significant heterogeneity among the studies $\left(\mathrm{I}^{2}=49 \%, \mathrm{P}=0.12\right)$. The pooled analysis with fixed-effects model showed no significant difference in the anesthesia time between the two groups (SMD, -0.10; $95 \% \mathrm{CI},-0.35$ to $0.15 ; \mathrm{P}=0.43$ ).

\section{Time taken to open eyes}

As shown in figure $2 \mathrm{~b}$, all five included studies $[1,8,14-16]$ reported data on the emergence times from the end of anesthesia to eye opening. Our analysis showed that $\mathrm{I}^{2}=85 \%$ and $\mathrm{P}<0.0001$, indicating the studies were significant heterogeneous. Therefore, the random-effect model was used. Pooled results demonstrated that the time taken to open eyes was significantly shorter in the desflurane group when compared with the sevoflurane group (SMD, $-0.63 ; 95 \% \mathrm{CI},-1.23$ to $-0.03 ; \mathrm{P}=0.04$ ).

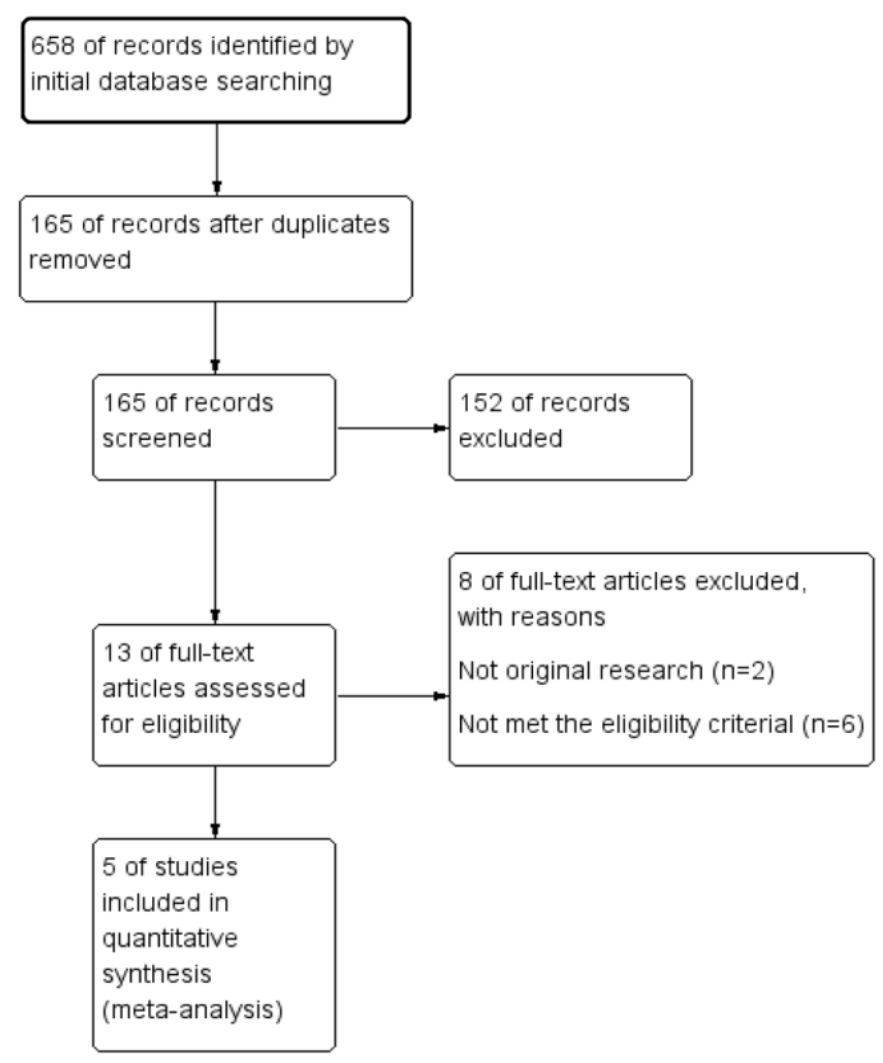

Figure 1. Flow diagram of the study selection process for the meta-analysis

\section{Time taken to extubation}

There were five studies $[1,8,14-16]$ evaluated the time until extubation. There was significant heterogeneity among the studies (I2=84\%, $\mathrm{P}<0.0001)$, therefore, a random-effects model was applied. Meta-analysis showed that time until extubation was significantly shorter in the desflurane group compared to the sevoflurane group (SMD, $-0.77 ; 95 \% \mathrm{CI},-1.35$ to $-0.19 ; \mathrm{P}=0.009$ ). As shown in figure 2c.

\section{Time taken to follow commands}

Among the trials included in our Meta-analysis, 4 studies $[8,14$ 16] included 288 patients reported the data the emergence times from the end of anesthesia to following commands. There was obvious heterogeneity among these studies ( $\mathrm{I} 2=90 \%, \mathrm{P}<0.00001)$, so the random-effects model was applied to pool the outcomes. The pool results indicated the desflurane group had a significantly shorter the time taken to follow commands when compared to the sevoflurane group (SMD, $-0.97 ; 95 \% \mathrm{CI},-1.76$ to $-0.19 ; \mathrm{P}=0.01$ ). As shown in figure $3 \mathrm{a}$.

\section{Time taken to orientation}

As shown in figure $3 \mathrm{~b}$, there were four studies $[1,8,14,16]$ reported data on the time taken to orientation. Significant heterogeneity was examined among the studies $\left(\mathrm{I}^{2}=90 \%, \mathrm{P}<0.00001\right)$. Therefore, the pooled analysis with the random-effects model showed that the emergence time from the end of anesthesia to orientation was significantly shorter in the desflurane group than the sevoflurane group (fixed-effect model; SMD, -1.49 ; $95 \%$ CI, -2.43 to -0.54 ).

\section{Length of PACU stay}

Four studies $[1,8,14,15]$ with 264 patients compared the length of $\mathrm{PACU}$ stay. There was no heterogeneity among studies $\left(\mathrm{I}^{2}=0 \%, \mathrm{P}=0.44\right)$. 
Table 1. Characteristics of the studies included in the review

\begin{tabular}{|l|l|l|l|l|l|l|l|}
\hline Author (year) & country & Interventions & Patients (n) & $\begin{array}{l}\text { Age(year) } \\
\text { (M } \pm \text { SD) }\end{array}$ & Gender (M/F) & $\begin{array}{l}\text { ASA } \\
\text { classification }\end{array}$ & Outcomes included in the meta-analysis \\
\hline Chen (2001) & USA & $\begin{array}{l}\text { Des } \\
\text { Sev }\end{array}$ & $\begin{array}{l}35 \\
35\end{array}$ & $\begin{array}{l}75 \pm 8 \\
73 \pm 9\end{array}$ & $\begin{array}{l}20 / 15 \\
18 / 17\end{array}$ & I-III & $\begin{array}{l}\text { Anesthesia time; Open eyes; Extubation; Following } \\
\text { commands; Orientation; PACU time }\end{array}$ \\
\hline Iannuzzi (2005) & Italy & $\begin{array}{l}\text { Des } \\
\text { Sev }\end{array}$ & 18 & $\begin{array}{l}71 \pm 3.8 \\
70 \pm 4.2\end{array}$ & $\begin{array}{l}5 / 9 \\
15 / 7\end{array}$ & Anesthesia time; Open eyes; Extubation; Orientation; \\
Nausea/vomiting; PACU time;
\end{tabular}

M/F: Male/Female, PACU: Postanesthetic Care Unit, Des: Desflurane, Sev, Sevoflurane

Table 2. Quality assessment of the included studies

\begin{tabular}{|c|c|c|c|c|c|c|}
\hline Author (year) & $\begin{array}{c}\text { Random sequence } \\
\text { Generation }\end{array}$ & $\begin{array}{c}\text { Allocation } \\
\text { Concealment }\end{array}$ & $\begin{array}{c}\text { Blinding of } \\
\text { participants and } \\
\text { personnel }\end{array}$ & $\begin{array}{c}\text { Blinding of outcome } \\
\text { assessment }\end{array}$ & $\begin{array}{c}\text { Incomplete outcome } \\
\text { data }\end{array}$ & Selective reporting \\
\hline Chen (2001) & Yes & Unclear & Yes & Yes & Yes \\
\hline Iannuzzi (2005) & Yes & Yes & Yes & Yes & Yes \\
\hline Rortgen (2010) & Yes & Yes & Yes & Yes & Yes \\
\hline Deepak (2013) & Yes & Yes & Yes & Yes & Yes \\
\hline Pakpirom (2016) & Yes & Yes & Yes & Yes & Yes & Yes \\
\hline
\end{tabular}

\section{a}

\begin{tabular}{|c|c|c|c|c|c|c|c|c|c|}
\hline a & Des & flurane & & Sev & ofluran & & & d. Mean Difference & \\
\hline Study or Subgroup & Mean & SD & Total & Mean & SD & Total & Weight & IV. Fixed. $95 \%$ C & $1 Y_{e}$ \\
\hline Chen (2001) & 155 & 42 & 35 & 161 & 39 & 35 & $29.1 \%$ & $-0.15[-0.62,0.32]$ & 200 \\
\hline lannuzzi (2005) & 68 & 8.4 & 18 & 64 & 10.3 & 18 & $14.6 \%$ & $0.42[-0.25,1.08]$ & 200 \\
\hline Deepak (2013) & 145.33 & 40.77 & 30 & 140.57 & 35.26 & 30 & $24.9 \%$ & $0.12[-0.38,0.63]$ & 20 \\
\hline Pakpirom (2016) & 138 & 50.9 & 42 & 170.8 & 83.16 & 36 & $31.4 \%$ & $-0.48[-0.93,-0.03]$ & 20 \\
\hline $\begin{array}{l}\text { Total }(95 \% \mathrm{Cl}) \\
\text { Heterogeneity: Chi² }\end{array}$ & & & $\begin{array}{c}125 \\
12): l^{\prime}\end{array}$ & & & 119 & $100.0 \%$ & $-0.10[-0.35,0.15]$ & \\
\hline
\end{tabular}

Heterogeneity: $\mathrm{Chi}^{2}=5.84, \mathrm{df}=3(\mathrm{P}=0.12) ; 1^{2}=49 \%$

b

\begin{tabular}{|c|c|c|c|c|c|c|c|}
\hline U & Des & lurar & & Sev & flura & & \\
\hline Study or Subgroup & Mean & SD & Total & Mean & SD & Total & Weight \\
\hline Chen (2001) & 6.3 & 2.4 & 35 & 8 & 2.8 & 35 & $20.6 \%$ \\
\hline Iannuzzi (2005) & 9.7 & 0.6 & 18 & 8.5 & 4.2 & 18 & $18.5 \%$ \\
\hline Rortgen (2010) & 7.4 & 3.7 & 40 & 9.2 & 4.3 & 40 & $21.0 \%$ \\
\hline Deepak (2013) & 5.4 & 1 & 30 & 7.9 & 1.5 & 30 & $19.0 \%$ \\
\hline Pakpirom (2016) & 7.5 & 3.4 & 42 & 9.6 & 4.6 & 36 & $20.9 \%$ \\
\hline
\end{tabular}

Std. Mean Difference

IV. Random. $95 \% \mathrm{Cl}$ Year $-0.64[-1.13,-0.16] 2001$ $0.39[-0.27,1.05] 2005$ $-0.44[-0.89,-0.00] 2010$ $-1.94[-2.56,-1.32] 2013$ $-0.52[-0.97,-0.07] 2016$

Heterogeneity: $\mathrm{Tau}^{2}=0.40 ; \mathrm{Chi}^{2}=27.10, \mathrm{df}=4(\mathrm{P}<0.0001): \mathrm{I}^{2}=85 \%$

$-0.63[-1.23,-0.03]$

Test for overall effect: $Z=2.04(P=0.04)$

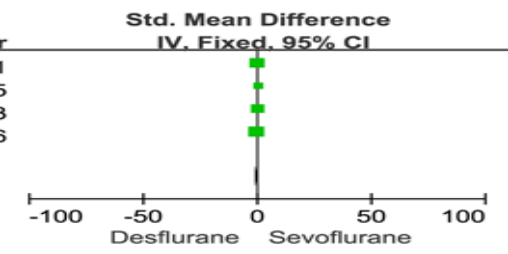

C Desflurane Sevoflurane

\begin{tabular}{lrrrrrrr} 
Study or Subgroup & Mean & SD & Total & Mean & SD & Total & Weight \\
\hline Chen (2001) & 7.1 & 2.9 & 35 & 8.6 & 3.7 & 35 & $20.8 \%$
\end{tabular}

Chen (2001)

lannuzzi (2005)

Rortgen (2010)

Pakpirom (2016)

$\begin{array}{lllllll}6.8 & 1.2 & 18 & 7.5 & 1.6 & 18 & 18.4 \%\end{array}$

$\begin{array}{lllllll}7.7 & 3.6 & 40 & 9.4 & 4.3 & 40 & 21.2 \%\end{array}$

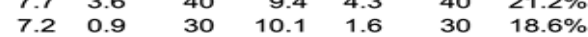

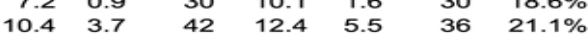

Total (95\% Cl)

165

$159100.0 \%$

Heterogeneity: $\mathrm{Tau}^{2}=0.36 ; \mathrm{Chi}^{2}=24.84, \mathrm{df}=4(\mathrm{P}<0.0001) ; \mathrm{I}^{2}=84 \%$

Test for overall effect: $Z=2.60(P=0.009)$

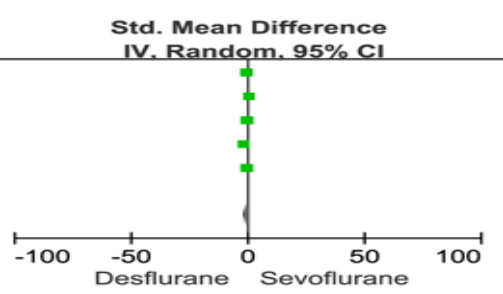

Std. Mean Difference

V. Random. $95 \% \mathrm{Cl}$ Year

$-0.45[-0.92,0.03] 2001$

$-0.48[-1.15,0.18] 2005$

$-0.42[-0.87,0.02] 2010$

$-2.21[-2.86,-1.55] 2013$

$-0.77[-1.35,-0.19]$

Std. Mean Difference

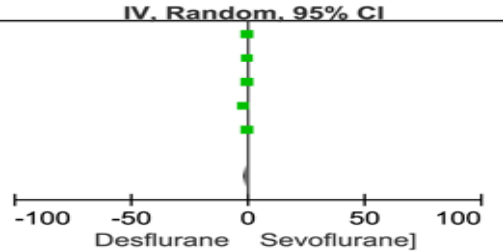

Figure 2. Forest plot of outcome of meta-analysis of RCTs regarding (a) Anesthesia time, (b) Time taken to open eyes, (c) Time taken to extubation

Results of the pooled data indicated there was no statistically significant difference between the two groups when comparing the PACU time (SMD, -4.65 ; 95\% CI, -10.31 to $1 ; \mathrm{P}=0.11$ ) (Figure 3c).

\section{Discussion}

There is great concern about the efficacy and safety of anesthetics in elderly patients. The present meta-analysis, involving 324 patients included from the five eligible studies, was performed to assess the efficacy desflurane and sevoflurane in elderly patients during general anesthesia. Our analysis screened one study published during the 2 years since previous meta-analysis [18]. The clinical utility of the previous meta-analyses is still uncertain because of one RCT [19] (Comparative Study of Desflurane and Sevoflurane in Elderly Patients Anesthesia.) do not give a complete description of the distribution of hidden, the specific random method. In our present paper, this metaanalysis has been boosted by data from a high quality study [14]. It is well established that desflurane anaesthesia in elderly patients was significantly associated with a faster early recovery than sevoflurane anaesthesia, including shorter the time taken to open the eyes (SMD, -0.63 ; $95 \% \mathrm{CI},-1.23$ to -0.03 ; $\mathrm{P}=0.04$ ), extubation (SMD, -0.77 ; $95 \% \mathrm{CI}$, -1.35 to $-0.19 ; \mathrm{P}=0.009$ ), follow commands (SMD, $-0.97 ; 95 \% \mathrm{CI},-1.76$ to $-0.19 ; \mathrm{P}=0.01$ ) and orientation (SMD, $-1.49 ; 95 \% \mathrm{CI},-2.43$ to -0.54 ). 
a

\begin{tabular}{|c|c|c|c|c|c|c|c|c|c|c|c|c|c|}
\hline \multirow[b]{2}{*}{ Study or Subgroup } & \multicolumn{3}{|c|}{ Desflurane } & \multicolumn{3}{|c|}{ Sevoflurane } & \multicolumn{3}{|c|}{ Std. Mean Difference } & \multirow{2}{*}{\multicolumn{4}{|c|}{$\begin{array}{l}\text { Std. Mean Difference } \\
\text { IV. Random. } 95 \% \mathrm{Cl}\end{array}$}} \\
\hline & Mean & SD & Total & Mean & SD & Total & Weight & IV. Random. $95 \% \mathrm{Cl}$ & Year & & & & \\
\hline Chen (2001) & 8 & 2.7 & 35 & 12.5 & 7.4 & 35 & $25.3 \%$ & $-0.80[-1.29,-0.31]$ & 2001 & & & & \\
\hline Rortgen (2010) & 7.7 & 3.6 & 40 & 9.2 & 4.6 & 40 & $25.8 \%$ & $-0.36[-0.80,0.08]$ & 2010 & & & & \\
\hline Deepak (2013) & 8.8 & 1.3 & 30 & 12.7 & 1.8 & 30 & $23.2 \%$ & $-2.45[-3.13,-1.77]$ & 2013 & & & & \\
\hline Pakpirom (2016) & 10.4 & 3.7 & 42 & 12.4 & 5.5 & 36 & $25.7 \%$ & $-0.43[-0.88,0.02]$ & 2016 & & & & \\
\hline Total $(95 \% \mathrm{Cl})$ & & & 147 & & & 141 & $100.0 \%$ & $-0.97[-1.76,-0.19]$ & & & & & \\
\hline $\begin{array}{l}\text { Heterogeneity: Tau² } \\
\text { Test for overall effec }\end{array}$ & $\begin{array}{l}57 ; \mathrm{Ch} \\
=2.44\end{array}$ & $=2$ & $\begin{array}{l}04, d \\
01)\end{array}$ & $3(P$ & 0 & $01) ; 1^{2}$ & $=90 \%$ & & & $\stackrel{\longmapsto}{-100}$ & $\begin{array}{c}-50 \quad 0 \\
\text { Desflurane }\end{array}$ & $\begin{array}{l}0 \\
0 \\
\text { Sevoflurane }\end{array}$ & 100 \\
\hline
\end{tabular}

b

\begin{tabular}{|c|c|c|c|c|c|c|c|c|c|c|c|c|c|}
\hline \multirow[b]{2}{*}{ Study or Subgroup } & \multicolumn{3}{|c|}{ Desflurane } & \multicolumn{3}{|c|}{ Sevoflurane } & \multicolumn{3}{|c|}{ Std. Mean Difference } & \multirow{2}{*}{\multicolumn{4}{|c|}{$\begin{array}{l}\text { Std. Mean Difference } \\
\text { IV. Random, } 95 \% \mathrm{Cl}\end{array}$}} \\
\hline & Mean & SD & Total & Mean & SD & Total & Weight & IV. Random. $95 \% \mathrm{CI}$ & Year & & & & \\
\hline Chen (2001) & 9.5 & 2.8 & 35 & 12.8 & 8.1 & 35 & $26.3 \%$ & $-0.54[-1.02,-0.06]$ & 2001 & & & & \\
\hline lannuzzi (2005) & 13.9 & 2.1 & 18 & 19.2 & 2.5 & 18 & $22.9 \%$ & $-2.24[-3.10,-1.39]$ & 2005 & & & & \\
\hline Deepak (2013) & 10.8 & 4.5 & 40 & 13.4 & 1.2 & 40 & $26.4 \%$ & $-0.78[-1.24,-0.33]$ & 2013 & & & & \\
\hline Pakpirom (2016) & 9.63 & 1.4 & 30 & 13.8 & 1.8 & 30 & $24.4 \%$ & $-2.55[-3.24,-1.86]$ & 2016 & & & & \\
\hline Total $(95 \% \mathrm{CI})$ & & & 123 & & & 123 & $100.0 \%$ & $-1.49[-2.43,-0.54]$ & & & & & \\
\hline $\begin{array}{l}\text { Heterogeneity: } \mathrm{Tau}^{2}= \\
\text { Test for overall effect }\end{array}$ & $\begin{array}{l}0.82 ; \mathrm{Cr} \\
\mathrm{Z}=3.09\end{array}$ & $\begin{array}{l}=3 \\
P=\end{array}$ & $\begin{array}{l}.89, \mathrm{df} \\
.002)\end{array}$ & $=3(P$ & 0.0 & $01) ; 1^{2}$ & $2=90 \%$ & & & $\longmapsto_{-100}$ & $\begin{array}{l}-50 \\
\text { Desflurane }\end{array}$ & $\begin{array}{l}0 \\
0 \\
\text { Sevoflurane }\end{array}$ & $\overrightarrow{100}$ \\
\hline
\end{tabular}

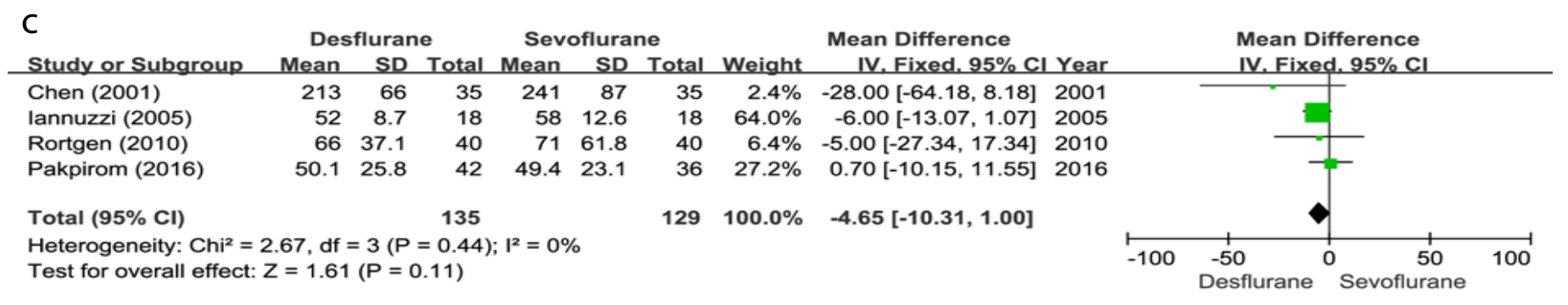

Figure 3. Forest plot of outcome of meta-analysis of RCTs regarding (a) Time taken to follow commands, (b) Time taken to orientation, (c) Length of PACU stay

However, there was no obvious statically difference in anesthesia time (SMD, $-0.10 ; 95 \% \mathrm{CI},-0.35$ to $0.15 ; \mathrm{P}=0.43$ ) and the length of PACU stay (SMD, $-4.65 ; 95 \% \mathrm{CI},-10.31$ to $1 ; \mathrm{P}=0.11$ ). These results are agreement with to another previous published study [20].

Though the mean time taken to open the eyes, extubation, follow commands and orientation were significantly shorter in the desflurane group than in the sevoflurane group in our analysis, there were high heterogeneity examined among the studies. We speculated the high heterogeneity may be due to each study calculated the time using different criteria. Furthermore, the experience of surgeons and anesthesiologists, and patient characteristics were likely the primary factors affecting the time for recovery.

Despite the studies included in this meta-analysis provided evidence favoring desflurane, several potential limitations should be mentioned. First, Only five RCTs were included, which limited our ability to performed subgroup analyses for some outcomes, therefore, we could not determine the source of heterogeneity. Second, some of the included had a relatively small the sample size, which might have impacted the reliability of the conclusion. Third, each RCT in this meta-analysis was conducted in a different country; therefore, people with different genetic constitutions may have had different responses to identical anaesthetic. Finally, because of lack of adequate data in some studies, we did not assess other possible events, except for those aforementioned results, including Nausea/vomiting, postoperative cognitive dysfunction et al. Although these mentioned shortcomings may lower the reliance of our conclusion, our study systematically assessed the efficacy of of desflurane and sevoflurane in elderly patients under anaesthesia. Meanwhile, some well-designed, large, and multi- center randomized controlled clinical trials are desperately welcomed to obtain further evidence.

In conclusion, this meta-analysis provides some baseline understanding and available information that desflurane had similar efficacy to sevoflurane in terms of the length of PACU stay. However, several potential advantages, such as shorter time to open the eyes, extubation, follow commands and orientation, were observed in desflurane group.

\section{Authors' contributions}

Yiping Li contributed to the study design and write. Ruiming Deng and Juan Zhou performed data collection and data analysis. Shifu $\mathrm{Hu}$ and Aiping Ouyang performed manuscript editing. All authors read and approved the final manuscript.

\section{References}

1. Iannuzzi E, Iannuzzi M, Viola G, Cerulli A, Cirillo V, et al. (2005) Desflurane and sevoflurane in elderly patients during general anesthesia: a double blind comparison. Minerva Anestesiol 71: 147-155. [Crossref]

2. Meineke M, Applegate RL 2nd, Rasmussen T, Anderson D, Azer S, et al. (2014) Cognitive dysfunction following desflurane versus sevoflurane general anesthesia in elderly patients: a randomized controlled trial. Med Gas Res 4: 6. [Crossref]

3. Harvey A, Montezano AC, Touyz RM (2015) Vascular biology of ageing-Implications in hypertension. J Mol Cell Cardiol 83: 112-121. [Crossref]

4. van Beek JH, Kirkwood TB (2016) Understanding the physiology of the ageing individual: computational modelling of changes in metabolism and endurance. Interface Focus 6: 20150079. [Crossref]

5. Waddle JP, Evers AS, Piccirillo JF (1998) Postanesthesia care unit length of stay: quantifying and assessing dependent factors. Anesth Analg 87: 628-633. [Crossref] 
6. Dogru K, Yildiz K, Madenoglu H, Boyaci A (2003) Early recovery properties of sevoflurane and desflurane in patients undergoing total hip replacement surgery. Curr Ther Res Clin Exp 64: 301-309. [Crossref]

7. Panagiotis K, Maria P, Argiri P, Panagiotis S (2005) Is postanesthesia care unit length of stay increased in hypothermic patients? AORN J 81: 379-382, 385-92. [Crossref]

8. Chen X, Zhao M, White PF, Li S, Tang J, et al. (2001) The recovery of cognitive function after general anesthesia in elderly patients: a comparison of desflurane and sevoflurane. Anesth Analg 93: 1489-1494. [Crossref]

9. Ramaiah R, Lam AM (2009) Postoperative cognitive dysfunction in the elderly. Anesthesiol Clin 27: 485-496, table of contents. [Crossref]

10. Magni G, Rosa IL, Melillo G, Savio A, Rosa G (2009) A comparison between sevoflurane and desflurane anesthesia in patients undergoing craniotomy for supratentorial intracranial surgery. Anesth Analg 109: 567-571. [Crossref]

11. White PF, Tang J, Wender RH, Yumul R, Stokes OJ, et al. (2009) Desflurane versus sevoflurane for maintenance of outpatient anesthesia: the effect on early versus late recovery and perioperative coughing. Anesth Analg 109: 387-393. [Crossref]

12. Tachibana S, Hayase T, Osuda M, Kazuma S, Yamakage M (2015) Recovery of postoperative cognitive function in elderly patients after a long duration of desflurane anesthesia: a pilot study. $J$ Anesth 29: 627-630. [Crossref]

13. Larsen B, Seitz A, Larsen R (2000) Recovery of cognitive function after remifentanilpropofol anesthesia: a comparison with desflurane and sevoflurane anesthesia. Anesth Analg 90: 168-174. [Crossref]
14. Pakpirom J, Kraithep J, Pattaravit N (2016) Length of postanesthetic care unit stay in elderly patients after general anesthesia: a randomized controlled trial comparing desflurane and sevoflurane. J Clin Anesth 32: 294-299. [Crossref]

15. Rortgen D, Kloos J, Fries M, Grottke O, Rex S, et al. (2010) Comparison of early cognitive function and recovery after desflurane or sevoflurane anaesthesia in the elderly: a double-blinded randomized controlled trial. Br J Anaesth 104: 167-174. [Crossref]

16. Deepak TS, Vadlamani S, Kumar KS, Kempegowda P (2013) Post-operative cognitive functions after general anesthesia with sevoflurane and desflurane in South Asian elderly. Middle East J Anaesthesiol 22: 143-148. [Crossref]

17. Higgins JP, Altman DG, Gøtzsche PC, Jüni P, Moher D, et al. (2011) The Cochrane Collaboration's tool for assessing risk of bias in randomised trials. BMJ 343: $\mathrm{d} 5928$ [Crossref]

18. Chen G, Zhou Y, Shi Q, Zhou H (2015) Comparison of early recovery and cognitive function after desflurane and sevoflurane anaesthesia in elderly patients: A metaanalysis of randomized controlled trials. $J$ Int Med Res 43: 619-628. [Crossref]

19. Zhang, H (2010) Comparative Study of Desflurane and Sevoflurane in Elderly Patients Anesthesia. Clinical Medicine \& Engineering: 65-66. [In Chinese].

20. Heavner JE, Kaye AD, Lin BK, King T (2003) Recovery of elderly patients from two or more hours of desflurane or sevoflurane anaesthesia. Br J Anaesth 91: 502-506. [Crossref]

Copyright: (C2018 Li Y. This is an open-access article distributed under the terms of the Creative Commons Attribution License, which permits unrestricted use, distribution, and reproduction in any medium, provided the original author and source are credited. 